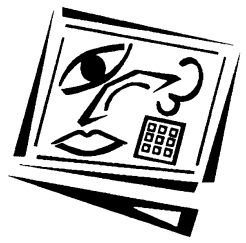

\title{
The search for learning community in learner paced distance education: Or, 'Having your cake and eating it, too!'
}

\author{
Terry Anderson, David Annand and Norine Wark \\ Athabasca University
}

\begin{abstract}
University distance and e-learning programs generally follow one of two models. Most dual mode institutions and some open universities follow a model of cohort learning. Students start and terminate each course at the same time, and proceed at the same pace. This model allows for occasional or regular group based activities. The second model, referred to as learner paced, is based on increased student independence. Students may start their courses at many points during the year, and complete these at their own pace, depending on the learner's circumstances and interests. It is much more challenging to integrate group based activities in this learner paced model. This study is situated in a university that supports continuous intake and learner pacing in its undergraduate programs. Athabasca University is investigating the feasibility and effectiveness of adding collaborative and cooperative learning activities to this model. The report summarises a study of learner interactions in the context of learner paced courses delivered by the University. Following a review of relevant literature, the study reports on interviews with Athabasca University faculty and external distance education experts, describes results from an online survey of undergraduate students, and documents how these findings may be operationalised at the University. An extensible model of community based learning support is proposed to utilise new social computing capabilities of the web, and to permit learner-learner interaction in a scaleable and cost effective manner, while retaining learner pacing.
\end{abstract}

\section{Introduction}

Meaningful group communication is perhaps the greatest pedagogical challenge in unpaced learning. (Paulsen, 2003, p.45.)

Most current designs for online courses reflect features of traditional universities. They generally have specified start and end dates, limited entry points, and consist of groups of students who proceed through each course at about the same pace. This "imposed pace" model lends itself to group based, online learning experiences. However, there is a tradition of 
open education that has sought to address the needs of learners who, for one reason or another, do not fit this classic mold of higher education. In these institutions, the primary objective of the learning model is to provide the greatest degree of access and flexibility for students.

As an open university, Athabasca University is committed to providing this flexibility in a number of ways. Anyone over the age of 15 may enroll in undergraduate courses. These courses may be challenged for credit. Students may apply to have non-formal learning experiences assessed for program credit. Courses are designed to facilitate independent learning. They may be started at any time during the year and completed at locations convenient to learners. Learners can proceed through these courses at their own pace. Assignments and exams can often be completed at any time, and in any order. This type of flexible learning is also referred to as "learner paced", "unpaced", "self study" or "independent study". For simplicity we refer to this type of programming as 'learner paced study' in this article. However, we note that some institutions (notably the British Open University) offer independent study courses that have only once per year start dates, and are significantly paced by the institution.

Independent learning designs dominated thinking and research on distance education for many years. Seminal distance education theorists including Holmberg (1989), Peters (1988) and Keegan (1990) celebrated the individualisation, learner freedom, and cost effectiveness of learner paced designs in the practice and even the definitions of distance education. They argued that learner paced study is an inherently superior form of higher education, because of its ability to overcome time and place constraints, and its economic scalability. Paulsen $(2003 ; 1993)$ argued in his 'theory of cooperative freedom' that many students seek freedom not only from place and time, but also freedom to choose type of media and content, times of access, and pace.

However, these very characteristics of learner paced study tend to restrict the ability of students to formally collaborate during their course work. Learner-learner interaction is one of the three fundamental modes of learning described by Moore (1989) and is critical in the reduction of 'transactional distance' (Moore, 1993) that contributes to drop out and dissatisfaction among distance education students. There is a growing body of literature indicating that increased peer interaction can boost participation and completion rates, and result in learning outcome gains in distance education courses (Shindler, 2004; Springer, Stanne, \& Donovan, 1999; Slavin, 1995). Interpersonal learning activities may also result in enhanced social integration of learners, and course and program completion rates in both campus and distance programs, and hence improve quality of learning, (Tinto, 1987; Sweet, 1986; Tinto, 1975). 
Imposed pacing as well as increased social presence and encouragement from peers within the learning community may account for higher completion rates in cohort based models compared to learner paced ones. For example, completion rates for learners in Athabasca University's learner paced undergraduate courses averaged $63.6 \%$ for the 2002-2003 academic year. Completion rates for the same courses offered in seminar format (either through synchronous technologies or face to face) averaged $86.9 \%$ over the same period (Athabasca University, 2003, p.12)

Thus, there appear to be valid arguments for both imposed pace and learner paced forms of distance education. Is it possible to marry the best of both approaches? At present we know very little from student, administrative and faculty perspectives about the effects of introducing peer collaboration in learner paced study environments. Nor do we know how to create and structure collaborative activities within learner paced study courses, so that desirable characteristics of both collaboration and learner pacing can be retained. Further, we know little about demographics, learning styles, attitudes or lifestyles of students who are more likely to appreciate and participate in collaborative activities at a distance. This type of knowledge could be used not only to develop more diverse learning activities but also to develop student services and tutorials that guide learners into course formats that are more appropriate for them.

This report examines the challenges and opportunities for enhancing peer communication, support, and cooperation while retaining learner paced characteristics in online courses. It summarises interviews with teachers and course developers at Athabasca University, and telephone interviews with educators at similar institutions in Europe and the US. It also reports on perceptions of value and use of online interaction among a sample of students in undergraduate, learner paced courses at Athabasca University. This information is used to develop a set of recommendations that can be incorporated by other distance education institutions seeking to combine the perceived advantages of learner paced education and online community. First, though, relevant literature is reviewed.

\section{Review of interaction literature}

Wagner (1994) defined interaction as "reciprocal events that require at least two objects and two actions. Interactions occur when these objects and events mutually influence one another" (p. 8). There is a wide body of distance and other education literature that explores the value of learnerlearner interactions and collaboration. Vygotsky (1978) argued that learning is fundamentally a social process carried on with the aid of mediated tools. He also contended that the most fruitful experiences in learners' educational processes occur when they interact, in a context, with 
more experienced partners or teachers who provide an "intellectual scaffold" that helps them perform complex tasks than would not be possible alone.

In adult learning, collaborative learning models are generally based upon constructivist theory. This assumes that the different perspectives, interests and skills that adults bring to the learning encounter provide additional resources to create knowledge and enhance learning through dialogue and joint production of "knowledge artifacts." For meaningful learning to occur, constructivism suggests that students need to explore subject matter in a broader context than provided in their reading materials - by sharing experiences and interacting, for example. Each type of instructional interaction plays a role in the entire educational process, with the process being more effective if the instructional design includes a variety of interactions.

Garrison (1989) argued that dialogue and debate were essential for learning, because these forms of two way communication allowed learners to negotiate and structure personally meaningful knowledge. Teaching necessarily transmitted societal knowledge, but a rounded learning experience needed to foster critical analysis in order to bring personal perspectives to bear and create new understanding for both the teacher and student.

Jonassen, Davidson, Collins, Campbell, \& Banaan-Haag (1995) developed this conception of online learning even further. To them, sustained two way asynchronous communication not only enables greater instructorlearner communication, but most importantly, enables the social construction of knowledge among learners at a distance. This effect occurs when online learning environments require, among others, "negotiation of meaning and reflection on what has been learned" (p. 21). Laurillard (2000) argued that a university education must go beyond access to information or content and include "engagement with others in the gradual development of their personal understanding" (p. 137). This engagement is developed through interaction between teachers and students and forms the basis of her "conversational" approach to the education process.

Other research in adult based distance education suggests value in techniques like peer tutoring and assessment (Ashwin, 2003; Damon, 1984). Peers can provide non-threatening, empathetic forms of support and instruction that often speak more directly to the learners than that provided by teachers coming from much different social and cognitive perspectives. Peer tutoring and teaching, especially at upper levels, has also been shown to reduce teacher workload in imposed pace courses without impairing the quality of the learning environment (Rourke \& 
Anderson, 2002). Also, for many learners, higher education is a social experience that provides opportunity for meeting new friends and building social networks. Such social networks can result in pleasurable personal relationships, enduring friendships, and professional contacts. Evidence from social network analysis also supports the value of membership by learners in diverse groups within vocational and personal domains (Watts, 2004).

However, experience has shown that building online learning communities requires commitment from all members. Students in a web based environment who are required to work collaboratively must commit increased time and develop new strategies to get to know each other, plan work together, and maintain effective communication (Mason, 1998).

\section{Value of learner paced learning}

On the other hand, learner paced models of education have demonstrable value in their own right, despite the difficulties for peer collaboration that result. Learner paced courses satisfy the desires of many adult learners for autonomy. In many instructional designs that are optimised for independent study, high quality learner-content interaction is substituted for learner-learner and learner-teacher interaction (Anderson, 2003).

Holmberg (1989) argued for the superiority of individualised interaction between student and teacher within traditional, independent study models of distance education. He conceptualised distance learning as essentially an individual act of internalisation. Dewey (1916) suggested that internal interaction is the defining component of the educational process that occurs when a learner transforms the inert information passed to them from another and constructs it into knowledge with personal application and value. Thus, Holmberg saw instructional design that supported learner autonomy and independence as important for learners at a distance. He asserted that distance education institutions needed to provide open access and learner paced courses, and should not require group based learning activities.

Others agreed with Holmberg that the more important characteristics of adult distance education consisted of learner independence and personal responsibility for educational outcomes and processes. Keegan (1990) characterised effective distance education processes as "reintegrating" the teaching and learning acts; that is, replicating as many of the attributes of face to face communication as possible, yet maintaining learner autonomy. Interpersonal communication at a distance did not need to be limited to more direct forms of instructor-learner interaction, such as telephone conversations or teleconferencing, but could also be recreated through 
appropriate design and use of printed instructional materials. Reintegration occurred when printed learning materials were easily understood, anticipated potential learner problems, provided carefully constructed course objectives and content, and contained ample practice questions and related feedback. These concepts are supported within online learning models that still rely heavily on learner-content interaction augmented by computer mediated and telephone interactions among students and learning staff, in large part because these designs are cost effective, scalable, and do not appear to affect learning efficacy (Clark, 1994).

Holmberg (1989) argued that creation of a personal voice and "guided didactic interaction" was possible in carefully structured, print based learning material. Today, more sophisticated electronic aids are used within instructional content to enhance learner-content interaction in the online environment through addition of Java applets, automated testing and quizzes that provide immediate feedback, simulations, adaptive computer assisted instruction, and other forms of digital learning objects.

This relatively distinct divide between theorists appears to be essentially unresolved at present. One view (represented by Holmberg and Keegan) conceptualises the process of distance education as being primarily flexible, learner paced learning that facilitates learner independence and autonomy. Others (such as Garrison) conceive the distance education process as now being transformed into one of sustained two way communication, where significant and frequent interaction between instructor and learner and among learners is the essential, enabling learning feature.

The failure to distinguish among relative degrees of pacing in distance education courses or programs, and the organisational and learning system differences that result, may account for varying conceptualisations in the literature of the appropriate means to achieve "interaction". Anderson (2003) noted that though constructivist learning theory necessitates learnerlearner interaction, this type of interaction is not essential for learning to occur within cognitive and behaviorist learning theories - except, for instance, when learning outcomes prescribe development of skills necessary to perform cooperative or essentially communicative tasks. Also, the value of interaction in the educational process and consequent creation of interdependence advocated by constructivists has at times been challenged by evidence that many students consciously choose learning activities that minimise their interactions with teachers and other students.

Discussions about the means, if any, to facilitate group collaboration in learner paced education models is notably absent from the literature. While technologies exist to facilitate synchronous and asynchronous forms of 
group interaction in imposed pace online learning environments, facilitating interaction among groups of learners in a learner paced setting is still problematic - and this despite rapid advances in technology and online learning management systems. This has likely occurred because most online learning systems have evolved from classroom based educational models and group based support systems (Ngwenya, Annand \& Wang, 2004). Learner paced online education must therefore address some important practical challenges in order to develop systems that facilitate group based learner interaction.

There may also be other pedagogical and administrative considerations that prevent or limit peer collaboration in online, learner paced environments. To further inform our understandings about these issues, we gathered information from educators and students. This process is described below.

\section{Research method}

Within Athabasca University, the investigators purposefully constructed a list of faculty members, instructional designers, and media developers experienced with designing courses for distance delivery. Face to face interviews were conducted with eight individuals who agreed to discuss their thoughts about providing collaborative learning experiences within online, learner paced courses. Each interview lasted between 30 and 60 minutes.

We also posted invitations on seventeen applicable listservs for non-AU faculty to participate in telephone interviews about the topic. Eighteen people responded to this initial request to participate. Nine other contacts were provided by information gathered from websites of the Canadian Association of Distance Education and the Open University of Hong Kong Electronic Library Distance Education Institute. Five additional people were identified during telephone interviews with initial interviewees.

Twenty-nine respondents were interviewed by telephone, two sent their replies via email and one participated through an online audio conference with the help of a translator. Each respondent received semi-structured interview questions in an email prior to participating in the interview. Telephone and audio conference interviews were recorded for all respondents. These were later transcribed, then analysed and grouped for reporting purposes by researcher identified themes.

All AU faculty who coordinate undergraduate learner paced courses were also canvassed by means of emails sent to applicable centre chairs and forwarded by them. Sixteen individuals responded to this email. 
In addition, students currently enrolled in researcher selected Athabasca University undergraduate, learner paced courses that contained some type of interactive activities were invited by email to complete an online survey. Students were given two weeks to complete the survey. One email reminder was sent.

\section{Results from faculty interviews}

External faculty respondents were very interested in this study, as might be expected from the self selecting nature of the sample. Several respondents indicated that they were either actively developing or delivering learner paced programming or interested in doing so. Respondents identified a variety of advantages and disadvantages to imposed pace and learner paced learning models. Most concurred that the educational value of a learning community provides greater learning opportunities for online students. One representative commentator stated,

In collaborative learning there are shared learning experiences, a bit of bench marking of standards between students as they progress, more choice in sub-groups, wider communities for such groups as gifted children, and better access and sharing of information and common materials. In many cases, learning becomes faster. It seems that online learning is an appropriate way for some students to learn.

Respondents suggested peer collaboration had value for several reasons. These, and representative comments where appropriate, are as follows:

1. Creating communities of inquiry.

Social interaction theories are key to learning. I believe that I learn and remember best when I can talk to others and work through the problem by getting feedback from others. This can be done verbally, textually or by other online means as well.

2. Developing communication, time management and teamwork skills.

3. Exposing students to others' questions.

[Collaborative online learning allows you to hear] the questions that others ask that you didn't think to ask, so that you learn more because it would not have even occurred to you to ask that.

4. Providing peer support.

With our Human Physiology course sometimes we have study buddies. Students will study together. That has worked really well in some cases when students are made aware that they can't just extract the information from each other but they learn together. 
5. Orientation to the relevant discipline.

Learning a subject in the social sciences requires learning the appropriate jargon. You have to practice using that jargon before you can fully understand it, so interaction is important. Working with the professors and other students helps you modify your understanding of these terms and becomes the very nature of the course itself.

6. Gaining intercultural perspectives.

Many [students] come from quite a diversity of backgrounds and they all have a lot of valuable insights to share and that certainly wouldn't happen if they just worked at home with their print-based assignments and talked with their tutor.

\section{Faster completion times}

We are finding that the ones that are more active in the community are finishing before the others. So the connection brings motivation.

It is of course possible that the students who are most motivated are also more likely to participate in collaborative activities and finish the course in quicker times. Thus, participation may be associated with, but not be a casual factor, in faster completion times. We know from our own students that there is great variation in the actual time taken to complete their courses.

Various problems with increased interaction and collaboration were also identified. Respondents noted that to be effective, collaborative and interactive activities must be designed and integrated into the course. In addition, efforts must be expended by institutional staff to promote, monitor, coordinate and assess these activities. Each of these activities takes time and resources. Usually the delivery model requires increased expenditures for student support, -including academic tutoring, and this does not scale well (Annand, 1999). As a result, collaboration models are less cost effective. As one interviewee noted,

Developing a community of learning is possible but the cost is high, possibly too high for the undergraduate level. At the graduate level, interaction is both feasible and valuable.

Building community is aided if students can easily interact with others. At present, this generally requires the release of personal information such as telephone or email addresses. To release such information without the explicit approval of students may be contrary to Freedom of Information and Protection of Privacy (FOIPP) regulations now in place in many jurisdictions. One respondent noted, 
It appears that there is a FOIPP prohibition on giving out student emails to other students in the course. If that is true, it would be a fundamental problem. This is problematic because you need to make exceptions for anyone who refuses. If you are doing group work in a course you can't have someone refuse.

Some respondents suggested advantages for learner paced study models. One noted,

[A learner-paced study model] lends itself to the competency-based (that is, skill development) model which has its own problems. The federal government spent a lot of money researching competency-based learning and found it to be very successful. Unfortunately, even with federal funding, the provincial governments did not buy into it - largely because the provincial governments were made up of bachelor-level university grads who had not experienced, and therefore, did not understand, the unpaced, competency-based model. Yet England and South America, for example, use this model quite successfully.

Some interviewees also noted that Athabasca University's undergraduate learning model supports learner paced study. Systems and facilities have been customised to support it. Changes that either permit or prescribe more collaborative approaches are often seen as "disruptive' to the institutional culture and difficult to implement. Thus, if ways can be found to increase learner learner interaction and develop and support community within a model of learner paced study, these are likely to be more readily adopted. An external respondent from a similar institution noted,

Our institute has a long history as a correspondence school. This kind of learning tends to focus on independent pacing. Other institutions coming from the virtual classroom metaphor would like to focus more on synchronous communication and common pacing. I think that is a different mind set and a fundamental difference between traditional $\mathrm{f}-2 \mathrm{-f}$ and correspondence schools.

Some respondents also argued that the imperative of lifelong learning implies development of study skills in a variety of modes and styles - not just when enrolled in a formal course, orchestrated by a teacher, and in the company of other students. Learner paced models encourage students to learn independently. This was perceived by some as a valuable skill for all citizens.

Others simply did not support the proposition that peer interaction created learning value. As one respondent noted,

Student interaction with teachers or students can be beneficial for student support, but is it necessary for learning? I have not seen any research that shows that it is necessary. 
Interviewees commented that students almost never complete discussions or other collaborative activities that are not awarded marks. Requiring participation only makes sense if the learning outcomes that result are sufficient to justify the reduction in learner control and flexibility that accompanies such prescribed activities. In some respondents' views, collaborative activities must be integrated into the course and accomplish identified learning objectives. One respondent noted,

If you add the interaction on as an afterthought to the course, then you are missing the whole point of the interaction. Right from the beginning we analyse tasks, determining if they are best accomplished alone, in small groups or whatever. Then we ask, 'how are we going to make this happen?'

Respondents also noted that the need for interaction is reduced because many students already have established learning communities. One interviewee's study of students' desires for interaction found that many students liked studying with friends while out for coffee, for example. The respondent suggested that interaction need not be student-to-student within a particular course to be beneficial, but could consist of other forms like employee-employee or employee-employer interaction. Another respondent noted that a community necessary for lifelong learning has to exist outside of a single structure, stating,

Why should people want to be part of a community? I am not sure that course-based learning, unpaced or paced, is compelling enough to engage the learner in that context because the course is not the thing they are there for - the community is bigger than that. It is something that has drawn them into this field of study. They have to be able to use what they are learning in their workplace.

A number of respondents described the challenges of creating a critical mass of students necessary to sustain a learning community in a learnerpaced environment, noting that is unlikely that sufficient numbers of students will be registered in low enrollment courses and be at approximately the same place to make collaborative activities possible. One respondent argued that this activity therefore should be used only in large enrolment courses, commenting,

A learning community is feasible with undergrads when you have a large number of students in a course. When you have enough students, there will be a certain number that move through at roughly the same pace - a cohort. It is almost like a mini-paced course within a large unpaced course. This cohort then can exchange and learn together as they go through.

The above discussion illustrates the complexity of the issue and the lack of unanimity about the relative value and cost of imposed and learner paced learning. We next turn to a survey of student opinion to gauge if their perceptions of the value of imposed pace instruction are equally bifurcated. 


\section{Results from student survey}

As noted above, a sample of students in several Athabasca University undergraduate courses was selected. Students were sent email questionnaires. These courses were chosen by the investigators because they had some form of online interaction built into them. They also represented a cross section of undergraduate disciplines with a wide range of enrollments. A total of 3,380 students across all courses were asked to participate. Of these requests, 209 email messages were not deliverable. In all, 388 or $12 \%$ of solicited students completed the survey. The somewhat low response rate may result from other work and family responsibilities that generally characterise students in leaner paced courses. Further, a significant number may have completed, not yet started or dropped out of a particular course at the time of the survey. Return rates for online surveys also have been consistently falling in recent years due primarily to spam and other information overload issues (Fraze, Hardin, Smith \& Lockaby 2002; Sheehan, 2001).

The respondents in general were experienced online and distance learners. The average number of online courses completed by each student was 2.1 with a range from 0 to 19 . The number of courses that were based on self study (that included older print based correspondence model courses) was only slightly lower $(\mathrm{m}=1.9$ range from $0-29)$. Besides other issues related to the non-random nature of the sample, it might be biased toward higher achieving students. About $93 \%$ of the student respondents predicted that they would receive either an A or a B in the course in which they were currently registered.

About $13 \%$ of the respondents reported working on a course at some time with other students registered in the same course, while $24 \%$ reported working with friends, family or co-workers. The majority of student respondents $(71 \%)$ chose not to participate in the interactive components of their courses, which consisted mostly of online discussion groups. Of the respondents who did participate in asynchronous conferences, $24 \%$ read or posted responses daily, 53\% participated once or twice per week; and the rest only a few times during the course. Most of the respondents (79\%) contributed 4-5 postings in each course.

The perceptions of value of the interactions by those who did participate were decidedly split. A summary of students' perceptions of the value of peer discussions is shown in Table 1.

Those students who did not choose to participate in discussion groups (71\% of the respondents) did so for a variety of reasons. $18 \%$ felt that participation would take too much time. A further $17 \%$ were not aware that 
discussion forums were available, 14\% thought that participation would not significantly increase their learning, and $10 \%$ indicated that they felt they had nothing to contribute. About $10 \%$ of respondents cited a lack of recent postings. Lack of technology to access the online discussion groups was indicated as a reason for non-participation by only $1 \%$ of the applicable respondents.

Table 1: Student Perception of value of online discussion groups ( $\mathrm{N}=104)$

\begin{tabular}{|c|c|c|c|c|c|}
\hline The online discussion groups: & $\begin{array}{c}\text { Strongly } \\
\text { agree }\end{array}$ & Agree & Neutral & Disagree & $\begin{array}{l}\text { Strongly } \\
\text { disagree }\end{array}$ \\
\hline Helped my progress & 11 & 43 & 23 & 18 & 6 \\
\hline Contributed to my learning & 12 & 43 & 26 & 16 & 7 \\
\hline $\begin{array}{l}\text { Contributed to my enjoyment } \\
\text { of the course }\end{array}$ & 15 & 45 & 17 & 15 & 7 \\
\hline $\begin{array}{l}\text { Helped me get to know other } \\
\text { students }\end{array}$ & 11 & 33 & 22 & 22 & 11 \\
\hline Was a waste of my time & 5 & 11 & 19 & 32 & 31 \\
\hline
\end{tabular}

Significantly, $78 \%$ of respondents either agreed or strongly agreed that they would interact with other students as long as they were able to proceed through the course at their own pace. When queried how they would like to interact, $70 \%$ preferred asynchronous media like email and computer conferencing, $27 \%$ preferred a combination of synchronous and asynchronous technologies, and only 3\% preferred synchronous interaction alone (for example, audio conferences or face to face interaction).

About $95 \%$ of student respondents reported a desire to access the work of students either currently or previously enrolled in the courses. About $77 \%$ of respondents indicated an interest in accessing animated learner-content interaction devices such as a "ChatBot." Only 25\% of students felt that participation should be graded.

The survey concluded by asking students if they would take part in any collaborative activities, however structured. About $49 \%$ indicated they would not; $29 \%$ indicated they would and $22 \%$ were unsure. When queried for the reasons that they did not wish to engage in collaborative activities, $58 \%$ said they preferred to learn on their own. About $25 \%$ indicated that they have a strong support group at work or at home, and $17 \%$ provided a variety of other reasons.

The survey results suggest that most current students choose not to participate in collaborative activities even if these activities are built into the course and participation could affect course marks. However, there was interest in enhanced forms of interaction with content and in the ability to view contributions of other students. Most also indicated an interest in 
collaborating, but not if such collaboration constrained their freedom to move through the course at their own pace.

In the final section of this paper, and based on the foregoing, we propose a learning support model that illustrates the means by which other learners, teachers or tutors, and learning content itself work together to facilitate learning in either imposed pace or learner paced courses.

\section{A model of learner support in learner paced courses}

Anderson (2003) noted that imposed pace and learner paced distance education models have different economic, pedagogical, and social assumptions. It is unlikely that either of these models alone will meet the needs of all learners or educational institutions. Nonetheless, it is both useful and strategically necessary for institutions engaged in distance and online education to continuously investigate and adjust their delivery models to accommodate both the largest number of students and any significant niche group of learners.

The "interaction equivalency theorem" (Anderson, 2003) proposes that meaningful learning experiences need only be supported by high levels of interactivity in one of three possible areas: learner-teacher, learner-learner, or learner-content. Interactions in the other two areas can be reduced or eliminated without affecting the quality of students' educational experiences. High levels of interaction in two or more areas may be more satisfying, but may lead to cost and learning time inefficiencies. Further, one type of interaction may be substituted for the other types with little or no loss in educational effectiveness. The goal of the model is to create a system that provides high quality, scalable education that is able to meet the growing demand for life long learning around the world. Figure 1 illustrates this model.

The model shows three critical components of any online learning system. The content and learner support services are basic components of most universities' online learning management systems; however, each needs to undergo continuous revision to insure that they exploit the new potentials of networked communication and information technologies. There are related pedagogical implications, For instance, rather than the progressing lockstep through pre structured content, students and instructors should be able to create diverse learning paths through an increasingly large set of learning alternatives (Koper, 2004a; Simon, Dolog., Miklós, Olmedilla, \& Sintek, 2004). 


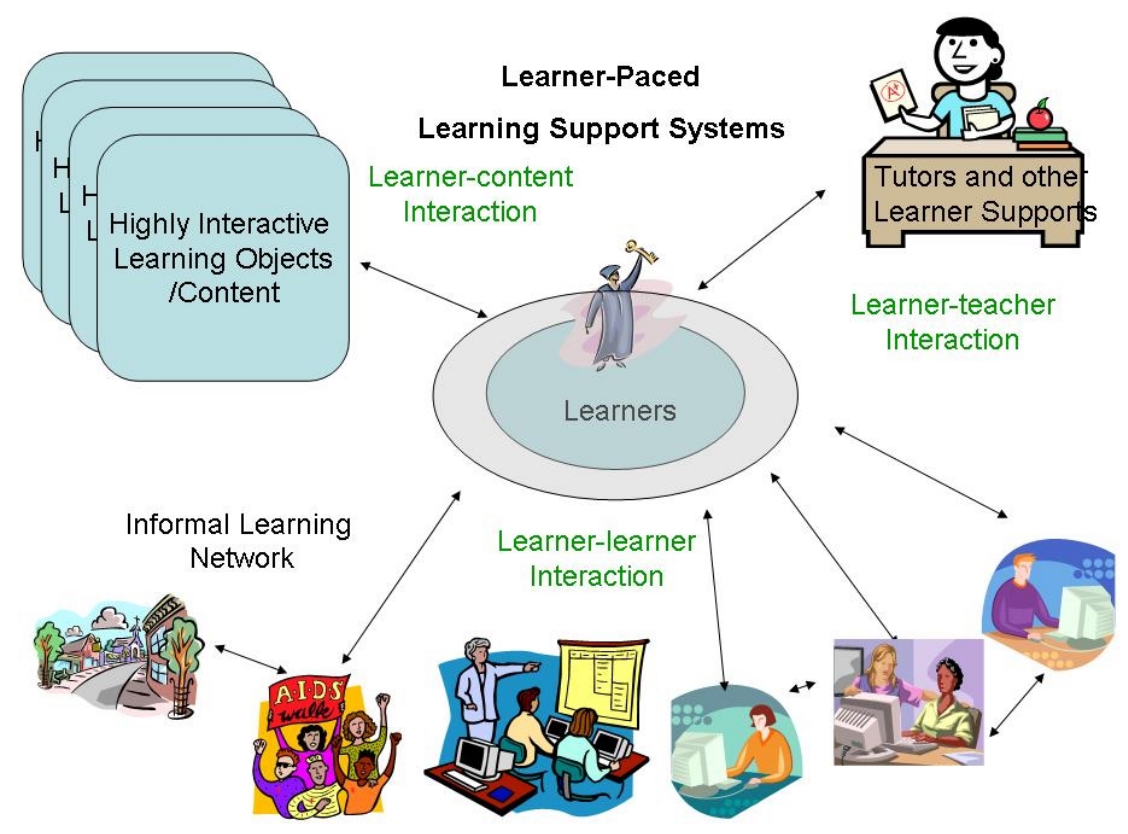

Figure 1 A proposed model of learner paced learning support

Learner-teacher interaction appears to carry the highest educational value among students, as they are willing to pay a premium for these learning experiences at other institutions and in Athabasca University graduate programs. However, this type of interaction does not lend itself to economies of scale. Also, the results of this study suggest that the more common model of cohort supported community that is dependent upon active teacher moderation may not be effective in learner paced courses. Learner-content interaction has often been substituted for learner-teacher interaction in mass education contexts. Ongoing technological advances mean that the cost of digital learning objects are generally falling while their learning effectiveness increases. The cost of such learning aids can also be amortised over growing student numbers. The combined economic effects of these factors argue for increased substitution of learner-content interaction for learner-learner and learner-teacher interactions.

There is little evidence to suggest that effective learning is dependent upon a cohort of students moving together in strict temporal sequence. However, there is evidence that providing opportunities for meaningful interaction 
with other students and community members in the context of structured learning activities enhances learning as well as course completion rates.

Rather than trying to devise additional student assessment incentives and support structures commonly suggested in the literature, we recommend that moderated, group based discussions should be de-emphasised. There may be rare exceptions where specific learning outcomes are prescribed to meet unique course outcomes - for example, to develop particular collaboration and communication skills in learners. However, in the majority of cases, new types of technologies that support the interaction needs of students in learner paced courses need to be developed.

Some critical features of this model include the ability for students to find and communicate with other students in their courses at learner determined times, and with a degree of social presence that meets their individual needs. Collaborative activities (when required) should be designed to allow students to work with other students enrolled in the course as well as other non-registered members within and outside of the learning community. Where required, systems should be designed to permit spontaneous formation of small groups (say 4-5 students) at a particular point in a course to perform a specified group task, after which the group would dissolve.

Alternatively, design of collaborative activities could involve members of the student's own virtual or place-bound communities. This type of informal networking is generally referred to as "social computing" (Shirkey, 2003; Davies, 2003; Kaplan-Leiserson, 2004; Levin, 2004). It can be supported through a variety of software tools and learning objects that encourage one on one or small group exchange, acquaintance, encouragement, and query. Students can locate learning partners and participate in a variety of informal discussion groups. Some of these may be directly related to course content, others to more general socialising, informal learning, employment and family concerns. This enhanced learning community could provide a referral service to its members for those seeking employment, advice, leads, personal support and resources, for instance.

One of the components of social interaction that is notably absent in both imposed pace and learner paced models is a sense of knowing if and when other learners are simultaneously engaged in a learning activity. In an interesting article based on a theoretical relationship between awareness of co-presence and development of communication episodes at the Open University of the Netherlands (OUNL), Kreijns \& Krischner (2001) describe a group awareness widget. This device operates in the virtual learning space to afford dialogue and collegial support much as a park bench does 
on a hiking trail. More recent work from the OUNL is focused on developing 'learning networks' in which students self select from multiinstitutional 'units of learning' as they create (and share) their own unique learning pathways (see Sloep, van Rosmalen, Brouns, van Bruggen, de Croock, Kester \& de Vries, 2004; or Koper, 2004b). These learning networks are congruous with the learning community model we present here.

Proponents of social software argue that these tools aid social relationships by "illuminating, codifying and tracking communication for good effect" (Davies, 2003). Many of the software solutions for effective online learning communities are still in developmental stages and many students have not had experience with these tools. Thus, a sustained developmental and research program is required to incorporate these into real communities of learning.

\section{Conclusion}

Emerging Internet based technologies create opportunities for new types of learning communities that allow learners around the globe to study at their own pace, yet engage in meaningful interactions with others - in essence, allowing them "to have their cake and eat it, too." The model presented in this paper can guide evolution to the next generation of distance education that incorporates these two elements. To realise and capitalise on new forms of learner paced education will require an ongoing commitment to innovation, experimentation and reflective study of our work, but it is within our grasp. Obviously, the conflicting evidence on the effect of interaction cited earlier, gives evidence of the need for more research focusing on more complex educational models and designs that account for the diverse needs of different learners, at different times, engaged in different contexts and studying different disciplinary content.

The model developed during this study describes one way of learning that accommodates student desire for increased autonomy and freedom. It is, in many ways, an instance of a postmodern university described by Raschke (2003) as "the efflorescent complexity of threads, links, sites, simulations, protocols, logics and connections that somehow earn the name of the 'the net'" p. 113.

\section{Acknowledgment}

The authors wish to acknowledge the support for this study provided by Athabasca University Research Committee's Mission Critical Research Fund, the interview work by Matt Rymer and the contribution of time provided by our internal and external interviewees and the students who completed our online survey. 


\section{References}

Annand, D. (1999). The problem of computer conferencing for distance-based universities. Open Learning, 14(3), 47-52.

Anderson, T. (2003). Getting the mix right: An updated and theoretical rational for interaction. International Review of Research in Open and Distance Learning, 4(2). http:/ / www.irrodl.org/content/v4.2/anderson.html

Ashwin, P. (2003). Peer facilitation and how it contributes to the development of a more social view of learning. Research in Post-Compulsory Education, 8(1), 5-18. [19 Apr 2005] http:/ /www.triangle.co.uk/rpe/

Athabasca University (2003). Report on Implementation of the Strategic University Plan, p.12.

Clark, R.E. (1994). Media will never influence learning. Educational Technology Research and Development, 42(2), 21-29.

Damon, W. (1984). Peer interaction: The untapped potential. Journal of Applied Developmental Psychology, 5, 331-343.

Davies, W. (2003) . You don't know me, but... Social capital and social software. London: Work Foundation. [19 Apr 2005]

http://www.theworkfoundation.com/research/isociety/social_capital_main.jsp

Dewey, J. (1916). Democracy and Education. New York: Macmillan. [19 Apr 2005] http:/ / www.worldwideschool.org/library/books/socl/education/Democracy andEducation/toc.html

Fraze, S., Hardin, K., Smith, J.H. \& Lockaby, J. (2002). The effects of delivery mode upon survey response rate and perceived attitudes of Texas agri-science teachers. In J. Kotrlik \& M. Burnett (Eds), National Agricultural Education Research Conference, 2002. [18 Aug 2004] http:/ / www.depts.ttu.edu/aged/research/frazesurvey.pdf

Garrison, D.R. (1989). Understanding distance education: A framework for the future. New York: Routledge.

Holmberg, B. (1989). Theory and practice of distance education. London: Routledge.

Jonassen, D., Davidson, M., Collins, M., Campbell, J. \& Banaan-Haag, B. (1995). Constructivism and computer mediated communication in distance education. American Journal of Distance Education, 9(2), 7-26.

Kaplan-Leiserson, A. (2004). We Learning: Social software and e-learning - Part 2. Learning Circuits, January. [19 Apr 2005] http:/ / www.learningcircuits.org/2004/jan2004/kaplan2.htm

Keegan, D. (1990). The foundations of distance education. (2nd ed.). London: Routledge. 
Koper, R. (2004a). Increasing learner retention in a simulated learning network using indirect social interaction. Learning Networks PrePrints Open University of the Netherlands. [19 Apr 2005]

http://dspace.learningnetworks.org/retrieve/506/preprint-LNsimulation.pdf

Koper, R. (2004b). Use of the Semantic Web to solve some basic problems in education: Increase flexible, distributed lifelong learning, decrease teacher's workload. Journal of Interactive Media in Education, 1 [19 Apr 2005] http:/ /wwwjime.open.ac.uk/2004/6.

Kreijns, K. \& Krischner, P. (2001). The social affordances of computer supported collaborative learning environments. IEEE Computer Society. [Oct 2004] http:/ / fie.engrng.pitt.edu/fie2001/papers/1104.pdf

Laurillard, D. (2000). New technologies and the curriculum. In P. Scott (Ed), Higher Education Re-formed. (pp. 133-153). London: Falmer Press.

Levin, A. (2004). Social Software: What's New. Many 2 Many. [19 Apr 2005] http://www.corante.com/many/archives/2004/10/18/social_software_whats_new.php

Mason, R. (1998). Globalising education: Trends and applications. London: Routledge.

Moore, M. (1989). Three types of interaction. American Journal of Distance Education, 3(2), 1-6.

Moore, M. G. (1993). Theory of transactional distance. In D. Keegan (Ed), Theoretical Principles of Distance Education. New York: Routledge.

Ngwenya, J., Annand, D. \& Wang, E. (2004). Supporting asynchronous discussions among online learners. In T. Anderson \& F. Elloumni (Eds), Theory and Practice of Online Learning. (pp. 319-348). Athabasca AB Canada: Athabasca University. [19 Apr 2005] http:/ /www.cde.athabascau.ca/online_book/

Paulsen, M. (1993). The hexagon of cooperative freedom: A distance education theory attuned to computer conferencing. DEOSNEWS, 3(2). [19 Apr 2005] http://www.nettskolen.com/forskning/21/hexagon.html

Paulsen, M. (2003). Online Education Learning Management Systems: Global e-Learning in a Scandinavian Perspective. Oslo, Norway: NKI Forlaget.

Peters, O. (1988). Distance teaching and industrial production: A comparative interpretation in outline. In D. Sewart, D. Keegan \& B. Holmberg (Eds), Distance Education: International Perspectives. (pp. 95-111). London/New York: CroomHelm/St. Martin's Press.

Raschke, C.A. (2003). The Digital Revolution and the Coming of the Postmodern University. New York: Routledge/Falmer.

Rourke, L. \& Anderson, T. (2002). Using peer teams to lead online discussions. Journal of Interactive Media in Education, 1. [19 Apr 2005] http://wwwjime.open.ac.uk/2002/1/ 
Sheehan, K.B. (2001). Email survey response rates: A review. Journal of Computer Mediated Communications, 6(2). [3 May 2003] http://www.ascusc.org/jcmc/vol6/issue2/sheehan.htm

Shindler, J. (2004). Greater than the sum of the parts? Examining the soundness of the collaborative exam in teacher education courses. Innovative Higher Education, 28(4), 273-283.

Shirkey, C. (2003). Social software and the politics of groups. [19 Apr 2005] http://www.shirky.com/writings/group_politics.html

Simon, B., Dolog, P., Miklós, Z., Olmedilla, D. \& Sintek, M. (2004). Conceptualising smart spaces for learning. Journal of Interactive Media in Education, 9. [19 Apr 2005] http:/ / www-jime.open.ac.uk/2004/9/

Slavin, R. (1995). Cooperative learning theory, research, and practice. Boston: Allyn and Bacon

Sloep, P., van Rosmalen, P., Brouns, F., van Bruggen, J., de Croock, M., Kester, L. \& de Vries, F. (2004). Agent support for online learning. Open Universiteit Nederland Educational Technology Expertise Centre. [19 Apr 2005] dspace.learningnetworks.org/retrieve/498/Agent_support_for_online_learning.pdf

Springer, L., Stanne, M. \& Donovan, S. (1999). Effects of small-group learning on undergraduates in science, mathematics, engineering and technology: A metaanalysis. Review of Educational Research, 16(1), 21-51.

Sweet, R. (1986). Applying Tinto's model of student dropout to distance education. Distance Education, 7(2), 201-213.

Tinto, V. (1975). Drop-out from higher education: A theoretical synthesis of recent research. Review of Educational Research, 45(1), 89-125.

Tinto, V. (1987). Leaving college: Rethinking the causes and cures of college attrition. Chicago, IL: University of Chicago Press.

Vygotsky, L. S. (1978). Mind in society, the development of higher psychological processes. Cambridge, MA: Harvard University Press.

Wagner, E. D. (1994). In support of a functional definition of interaction. The American Journal of Distance Education, 8(2), 6-26.

Watts, D. (2004). Six degrees: The science of a connected age. Norton: New York.

Terry Anderson, David Annand and Norine Wark, Athabasca University

Contact author: Terry Anderson

Professor and Canada Research Chair in Distance Education

Athabasca University, \#320 10030107 St, Edmonton AB Canada T5J3E4

Email: terrya@athabascau.ca 